\title{
Reuna
}

\section{QUALIDADE DE VIDA NO TRABALHO DE ELETRICITÁRIOS DO ESTADO DO CEARÁ}

\section{QUALITY OF WORK LIFE OF ELETRICY WORKERS IN THE STATE OF CEARÁ}

http://dx.doi.org/10.21714/2179-8834/2017v22n3p19-38

\author{
Luis Eduardo Brandão Paiva \\ Universidade Federal do Ceará - Programa de Pós-graduação em Administração e Controladoria, Brasil. \\ E-mail: eduardobrandao@alu.ufc.br
}

Tereza Cristina Batista de Lima

Universidade Federal do Ceará - Programa de Pós-graduação em Administração e Controladoria, Brasil. E-mail: tcblima@uol.com.br

\begin{abstract}
Alicia Serra Vasconcelos
Universidade Federal do Ceará - Programa de Pós-graduação em Administração e Controladoria, Brasil. E-mail: aliciavasconcelos@marquise.com.br

Sérgio Chaves Arruda

Universidade Federal do Ceará - Programa de Pós-graduação em Administração e Controladoria, Brasil. E-mail: sergioarruda@hotmail.com
\end{abstract}

Submissão: 19 Fev. 2017 Publicação: 06 Nov. 2017. Sistema de avaliação: Double blind review. Centro Universitário UNA, Belo Horizonte - MG, Brasil. Editor geral: Prof. Dr. Gustavo Quiroga Souki

Este artigo encontra-se disponível nos seguintes endereços eletrônicos: http://revistas.una.br/index.php/reuna/article/view/881 http://dx.doi.org/10.21714/2179-8834/2017v22n3p19-38

\section{RESUMO}

Este estudo apresenta a evolução dos conceitos relacionados à Qualidade de Vida no Trabalho (QVT), destacando seus principais modelos e instrumentos para avaliar a QVT nas organizações. Aborda, ainda, o conceito de periculosidade e as operações perigosas com energia elétrica. Este estudo objetiva, portanto, analisar a qualidade de vida no trabalho dos eletricitários do Estado do Ceará. Foi aplicada uma pesquisa junto a trabalhadores que lidam, diariamente, com a periculosidade, possibilitando, então, verificar se este fator influencia ou não a QVT desses indivíduos. A pesquisa quantitativa, de natureza descritiva, foi realizada por meio de uma amostra não probabilística junto a eletricitários do Estado do Ceará. O instrumento utilizado foi o QWLQ-bref (Questionário Abreviado de Qualidade de Vida no Trabalho), validado por Cheremeta et al. (2011), para a obtenção dos dados. Os resultados obtidos apontam para níveis satisfatórios de QVT, em que as análises dos domínios físico/saúde, psicológico, pessoal e profissional apresentaram índices satisfatórios. O estudo apresentado pode ser considerado um instrumento diagnóstico para gestores das empresas no setor elétrico, com o intuito de analisar os fatores considerados importantes para satisfação desses trabalhadores. Para outros estudos, recomendase, portanto, a inclusão de questões qualitativas para aprofundamentos sobre os domínios de QVT.

Palavras-chave: Qualidade de Vida no Trabalho (QVT), Eletricitários, Domínios de QVT. 


\section{ABSTRACT}

This study presents the evolution of concepts related to Quality of Work Life (QWL), highlighting its main models and instruments to evaluate QWL in organizations. It also addresses the concept of dangerousness and dangerous operations with electric power. This study aims, therefore, to analyze the quality of life in the work of electricians in the State of Ceará. A survey was applied to workers who deal daily with the hazard, making it possible to verify if this factor influences the QWL of these individuals. The quantitative research, of descriptive nature, was carried out by means of a non-probabilistic sample next to electricians of the State of Ceará. The instrument used was the QWLQ-bref (Abbreviated Questionnaire Quality of Work Life), validated by Cheremeta et al. (2011), in order to obtain the data. The results obtained point to satisfactory levels of QWL, in which the physical, health, psychological, personal and professional domains presented satisfactory indexes. The present study can be considered a diagnostic tool for managers of companies in the electric sector, with the purpose of analyzing the factors considered important for the satisfaction of these workers. For other studies, it is therefore recommended to include qualitative questions for in-depth studies on QWL domains.

Keywords: Quality of Work Life (QWL), Electricity workers, QWL domains.

\section{Introdução}

O trabalho deixou de ser fundamentalmente um meio de sobrevivência para ser uma maneira de realização pessoal, integração social e, consequentemente, de satisfação na vida dos indivíduos. Diante disso, torna-se pertinente para a alta gestão compreender como pode aumentar a satisfação e a qualidade de vida dos trabalhadores no contexto organizacional. A Qualidade de Vida no Trabalho (QVT) envolve as pessoas, o trabalho e a organização, ligando-se diretamente à tomada de decisão, assim como aos problemas no ambiente de trabalho (BORGES-ANDRADE; ZANELLI, 2002; CODO, 1999; SILVA; CAMPOS, 2017).

A satisfação no trabalho resulta da complexa e dinâmica interação das condições gerais de vida, das relações e processos de trabalho e do controle que os trabalhadores têm sobre suas condições de vida e de trabalho. O termo qualidade de vida apresenta, portanto, diversas contextualizações, podendo ser explicado de forma global, em que se enfatiza a satisfação geral com a vida; ou até mesmo dividida em componentes que unidos se aproximariam de um conceito mais geral. Dependendo da área de estudo pode ser sinônimo de saúde, de estilo de vida, de condições de vida, de felicidade e de satisfação pessoal (FARQUHAR 1995; MARQUEZE; MORENO 2005).

Diante disso, são apresentados diversos modelos que permitem avaliar a aplicabilidade da qualidade de vida para os trabalhadores, dentre os principais autores clássicos que desenvolveram modelos relacionados à QVT, destacam-se os modelos de Walton (1973), Hackman e Oldham (1975), Westley (1979), Werther e Davis (1981); Nadler e Lawler (1983) e Huse e Cummings (1985).

Para Limongi-França e Zaima (2002), Qualidade de Vida no Trabalho (QVT) é um conjunto das práticas de uma organização, o qual possibilita a implantação das melhorias e inovações gerenciais e tecnológicas no ambiente de trabalho. Portanto, 
percebe-se que existem diversos fatores do trabalho que afetam, diretamente, na qualidade de vida no trabalhador. Um desses fatores é a periculosidade, abordada mais profundamente nesta pesquisa, tendo em vista que foram escolhidos os indivíduos que trabalham, diretamente, com energia elétrica, que é uma das atividades consideradas perigosas, conforme a Lei $n^{\circ} 12.740$ (BRASIL, 2012).

Nesse contexto, surge o seguinte questionamento: qual o nível de qualidade de vida no trabalho de eletricitários do Estado do Ceará? Para tanto, a fim de responder ao questionamento são destacados os seguintes objetivos geral e específicos.

Esta pesquisa tem como objetivo geral, portanto, analisar os indicadores de Qualidade de Vida no Trabalho (QVT) dos eletricitários do Estado do Ceará. Os objetivos específicos são: (i) analisar os índices de QVT sobre o domínio físico/saúde; (ii) investigar os níveis de QVT sobre o domínio psicológico; (iii) avaliar os requisitos de QVT sobre o domínio pessoal; e (iv) investigar os índices de QVT sobre o domínio profissional.

Diante disso, identificam-se as seguintes hipóteses: $\mathrm{H} 1$ : Os eletricitários possuem índices neutros de QVT para o domínio físico/saúde; H2: Os eletricitários possuem índices satisfatórios para o domínio psicológico; H3: Os eletricitários possuem índices satisfatórios para o domínio pessoal; e H4: Os eletricitários possuem índices neutros para o domínio profissional.

Este estudo é considerado por sua natureza quantitativa, de caráter descritivo, junto a Eletricitários do Estado do Ceará. Foi utilizado o QWLQ-bref (Questionário Abreviado de Qualidade de Vida no Trabalho), validado por Cheremeta et al. (2011), no Brasil, que analisa os domínios físico/saúde, psicológico, pessoal e profissional de QVT.

O desenvolvimento de pesquisas acadêmicas como esta é considerada essencial, pois visa a melhoria da qualidade de vida para esses trabalhadores, como também objetiva fornecer às organizações um panorama sobre a produtividade, por parte desses funcionários, o que impacta diretamento na QVT. Ademais, estudos que alinham a QVT aos Eletricitários, os quais atuam nas atividades em condições de periculosidade, são escassos ou quase inexistentes, e isto possibilita contribuições empíricas e teóricas desta pesquisa.

Espera-se, então, que os resultados deste estudo possam fornecer aos gestores do setor eletricitário um instrumento de diagnóstico de QVT, o qual abrange, além desta, outras variáveis que impactam, diretamente, no desempenho do indivíduo no ambiente de trabalho, como clima, satisfação e bem-estar no trabalho.

\section{Referencial Teórico}

Pesquisas e teorias sobre o indivíduo e o comportamento humano, no que diz respeito à satisfação no trabalho, contribuem diretamente para o desenvolvimento dos estudos relacionados à Qualidade de Vida no Trabalho (QVT). Baseando-se, principalmente, nas escolas administrativas de pesquisa, autores se remetem a trabalhos essenciais para esses estudos, como Elton Mayo (1945), em Hawthorne; Maslow (1971), sobre a hierarquia de necessidades; McGregor (1960), com a teoria X e Y; e Herzberg (1987), mediante o conceito de enriquecimento do cargo. 
Os estudos desenvolvidos por Elton Mayo (1945), na "Western Eletric Company", demonstram um surgimento de preocupações sobre como os fatores externos podem influenciar na produtividade do trabalhador. Essas pesquisas, apesar de uma abordagem ainda científica, foram importantes para o estudo do comportamento humano e da qualidade de vida do trabalhador. Maslow (1971) aborda, por sua vez, a hierarquia de necessidades, composta por necessidades fisiológicas, de segurança, de amor, de estima e de auto realização. Inicialmente, foi defendida de forma sequencial e, posteriormente, de maneira menos rígida, ao afirmar que as pessoas podem se encontrar parcialmente satisfeitas e insatisfeitas em todas as suas necessidades fundamentais.

McGregor (1960), na teoria X, ressalta que os indivíduos têm aversão ao trabalho e o evitam, precisando, portanto, que os mesmos sejam controlados e coagidos para que os objetivos organizacionais e suas tarefas sejam cumpridos. Enquanto que na teoria $\mathrm{Y}$, o indivíduo busca satisfazer suas necessidades egoístas por meio do trabalho, estando disposto a se autocontrolar para isso, mediante recompensas associadas à realização das tarefas. De acordo com Herzberg (1987), os fatores que motivam o trabalho são aqueles que se referem diretamente à tarefa e a sua execução, em que a motivação e a produtividade têm uma relação de dependência. Herzberg (1987) identifica, ainda, dois fatores influenciadores para a satisfação do indivíduo: os motivadores ligados com a realização, reconhecimento do trabalho, desenvolvimento, responsabilidades e o próprio trabalho; enquanto que os de higiene se referem às condições de trabalho, remuneração, supervisão e situação.

A Qualidade de Vida (QV) pode ser influenciada pelo ambiente em que o ser humano interage com um conjunto de relações biológicas, religiosas, políticas, econômicas e culturais, visando, então, nessa interação que ambos sejam transformados. A QVT é a relação entre a QV do indivíduo dentro e fora do ambiente profissional, englobando pessoas, trabalho, organização e ambiente organizacional (PEREIRA; TEIXEIRA; SANTOS, 2012; SILVA; CAMPOS, 2017).

A evolução dos estudos de QVT teve o seu desenvolvimento com a finalidade de melhorar a eficácia organizacional, e para isso um requisito essencial é a satisfação do indivíduo por meio da participação nas decisões, bem como de condições favoráveis em seu trabalho. Durante esse processo, pesquisadores evoluíram seus estudos ao ponto de serem estruturados modelos de QVT, dentre os principais se destacam os modelos de: Walton (1973), Hackman e Oldham (1975), Westley (1979), Werther e Davis (1981), Nadler e Lawler (1983), Efraty, Sirgy e Claiborne (1991), Martel e Dupuis (2006) e Manojlovich e Laschinger (2007).

Walton (1973) aborda suas pesquisas sobre QVT baseadas em oito dimensões: compensação justa e adequada; segurança e saúde nas condições de trabalho; uso e desenvolvimento de capacidades; oportunidade de crescimento e segurança; integração social na organização do trabalho; constitucionalismo na organização do trabalho e a relevância social do trabalho na vida. Ademais, Westley (1979) analisa e classifica quatro problemas que afetam o ambiente de trabalho, no que diz respeito à QVT: o político, remetendo à insegurança; o econômico, enfatizando a injustiça; o psicológico, relacionado com a alienação; e o sociológico, relacionado com a autonomia. Hackman e Oldham (1975) elaboraram um estudo sobre QVT, no qual sua estratégia se baseava em cinco dimensões básicas do trabalho percebidas pelo indivíduo: variedade de habilidades; identidade da tarefa; significado da tarefa; autonomia e feedback. 
Werther e Davis (1981) dedicam sua pesquisa por meio da análise dos cargos e sua designação em três elementos, o primeiro se refere aos elementos organizacionais que são aqueles que medem a eficiência do projeto de cargos, o segundo se remete aos elementos ambientais relacionados ao ambiente externo da organização e o terceiro aborda os elementos comportamentais que são os mais sensíveis para o cargo. Na perspectiva de Nadler e Lawler (1983), o sucesso da QVT depende de alguns fatores: percepção da necessidade; foco no problema que é destacado na organização; estrutura para identificação e solução deste problema; compensações projetadas tanto para processos, quanto para resultados; e sistemas múltiplos afetados e envolvimento amplo da organização.

Efraty, Sirgy e Claiborne (1991) evidenciam, por sua vez, que a alienação pessoal tem um efeito negativo na identificação organizacional, relacionados aos aspectos ligados à QVT, como satisfação e envolvimento com o trabalho. Martel e Dupuis (2006) procuram alinhar conceitos relacionados à QVT, levando-se em conta uma perspectiva mais sistêmica, alinhando a qualidade de vida à qualidade de vida no trabalho. Além desses autores, Manojlovich e Laschinger (2007) relacionam a QVT aos profissionais de enfermagem, considerando, então, o empoderamento estrutural do trabalho na satisfação com o trabalho.

Durante a evolução nos estudos de QV e QVT nas organizações e na sociedade, verificam-se o desenvolvimento de questionários e instrumentos que buscam mensurar o nível de QV e QVT. Conforme Reis Junior, Pilatti e Pedroso (2012), o questionário QWQL-78 (Questionário de Qualidade de Vida no Trabalho) foi construído baseando-se, estruturalmente, no questionário WHOQOL-100 (Questionário de Qualidade de Vida da Organização Mundial de Saúde), o qual tem cem questões, compostas pelos domínios físico, psicológico, nível de dependência, relações sociais, ambiente e aspectos espirituais/religião/crenças pessoais.

Quanto à definição dos indicadores a serem avaliados, houve como referências, principalmente, os modelos de QVT de Walton (1973), Hackman e Oldham (1975), Westley (1979) e Werther e Davis (1983). Após estudo e formação desses indicadores, constituem-se setenta e oito questões, em que se optou organizálas em quatro grandes domínios, sendo estes: físico/saúde; psicológico; pessoal e profissional.

O domínio físico/saúde, de acordo com Reis Junior, Pilatti e Pedroso (2012), se refere aos aspectos relacionados à saúde, às doenças e aos hábitos saudáveis dos trabalhadores. Para a formação do questionário, Walton (1973) afirma que o trabalhador não deve passar por condições físicas e mentais que o prejudiquem no seu trabalho para ter uma boa QVT. É importante que as organizações forneçam subsídios para que as necessidades do trabalhador sejam atendidas. Limongi-França e Zaima (2002) colocam a segurança (conforto) como fator primordial para um bom desempenho em qualquer função. Além disso, a periculosidade e a insalubridade são fatores que podem influenciar diretamente nesse indicador.

No domínio psicológico integram-se aspectos relacionados com a satisfação pessoal, autocontrole, espírito de camaradagem, motivação, orgulho e autoestima dos trabalhadores (REIS JUNIOR; PILATTI; PEDROSO, 2012). Hackman e Oldham (1975) indicam que a QVT depende também dos níveis no qual o trabalho permite a liberdade, a independência e a autonomia na determinação da forma que pode ser utilizada para executar a atividade. Westley (1979) defende que a liberdade de 
expressão no trabalho é um fator importante para a organização e proporciona mais satisfação e QVT para os trabalhadores.

Com relação ao domínio pessoal, em conformidade com Reis Junior, Pilatti e Pedroso (2012), são abordados os aspectos familiares e culturais, crenças pessoais e religiosas, preconceito, mobilidade, respeito, entre outros. Walton (1973) defende que a qualidade do lazer e a forma como o tempo livre que o indivíduo tem são utilizados é um fator influenciador sobre a QVT dos indivíduos. Westley (1979) afirma que a partir do momento que o trabalhador tem suas crenças pessoais ou religiosas ignoradas, tende a ficar mais desmotivado.

No domínio profissional são integralizados os aspectos organizacionais que afetam na QV dos trabalhadores, como as condições de trabalho, imagem da empresa (orgulho), carreira, aprendizagem, cooperação entre níveis hierárquicos, remuneração e responsabilidade social (REIS JUNIOR; PILATTI; PEDROSO, 2012). Ademais, Werther e Davis (1983) remetem que o indicador de cooperação de níveis hierárquicos permite analisar a competência de relacionamento interpessoal e camaradagem, sejam próprias ou dos colegas, e isto permite que haja confiança mútua entre a equipe. O nível de desafio e a presença de metas e indicadores são também fatores motivadores para o trabalho.

Como os indivíduos investigados nesta pesquisa tratam periodicamente com atividades perigosas, no caso a energia elétrica, é fundamental entender o fator de trabalho periculosidade. De acordo com a Lei n 12.740 de 08 de Dezembro de 2012, que alterou o artigo 193 da Consolidação das Leis do Trabalho (CLT), a periculosidade pode ser caracterizada por um risco imediato que algumas atividades e operações podem proporcionar, dada a natureza ou método de trabalho que exige contato permanente do trabalhador com inflamáveis, explosivos ou energia elétrica. A caracterização legal da periculosidade é determinada por meio da Norma Regulamentadora 16 (NR-16).

Conforme o item 4, do anexo 4 da NR-16 (BRASIL, 2014), citam-se as seguintes atividades em condições de periculosidade com eletricidade:

a) montagem, instalação, manutenção, substituição, conservação em postes, torres, isoladores, entre outros;

b) corta e poda de árvores;

c) construção civil, instalação, substituição e limpeza de: valas, bancos de dados, dutos, condutos, caneletas, entre outros; e

d) serviços de limpeza, pintura e sinalização de instalações e equipamentos elétricos.

Essas atividades com Energia Elétrica são controladas pela NR-10 (BRASIL, 2004), com última atualização por meio da Portaria nำ 598, de 07 de dezembro de 2004, que regulamenta a segurança em instalações e serviços em eletricidade.

Atualmente, a principal consequência negativa que pode ocorrer com um indivíduo, que não possui o cuidado exigido para executar determinada tarefa, é o acidente de trabalho, de acordo com o Manual da Fundação Comitê de Gestão Empresarial - COGE (2013).

A Fundação COGE divulga, anualmente, o relatório de estatísticas de acidentes no setor elétrico brasileiro. O objetivo deste relatório é identificar os possíveis 
problemas e estimular soluções para o aperfeiçoamento da gestão de segurança e saúde no trabalho, bem como a redução dos acidentes no setor.

Os acidentados de origem elétrica representam $69 \%$ do total de acidentados fatais de contratadas, ou seja, os terceirizados são a maioria das vítimas fatais e mutiladas, assim como o índice de acidentados dos terceirizados é maior que o dos contratados, o que confirma que existe uma maior terceirização para as atividades de maior risco e que os acidentes estão diretamente ligados aos processos de trabalho. Apesar de o número de acidentados ainda ser elevado, conforme o Relatório da Fundação COGE (2013), percebe-se que ele está diminuindo. Isso se deve, principalmente, ao crescimento no investimento em segurança no trabalho por parte do governo e das empresas.

\section{Metodologia}

Esta pesquisa se classifica por sua natureza quantitativa, de caráter descritivo. Diante disso, tem-se o método survey, que é considerado o método de coleta de dados por meio da pesquisa de levantamento, uma vez que busca informações de percepções, de crenças e de costumes (BABBIE, 2005; GRAY, 2012).

A amostra escolhida, no caso em análise, refere-se aos trabalhadores de uma empresa terceirizada, prestadora de serviços em todo o Estado do Ceará. O método utilizado na escolha da amostra foi o não probabilístico e intencional, pois há uma escolha deliberada dos elementos da amostra, baseada no acesso à empresa e na disponibilidade dos profissionais dessa empresa em responder a pesquisa (BABBIE, 2005).

Para coleta de dados se utilizou um questionário estruturado, formado por onze questões referentes aos dados sócio demográficos dos respondentes. Além desse, aplicou-se também o questionário QWLQ-bref (Questionário Abreviado de Qualidade de Vida no Trabalho), versão abreviada do QWLQ-78.

O QWQL-bref tem como base o instrumento da OMS para medição de QV, o WHOQOL-bref e para formação dos seus indicadores foram utilizados, principalmente, os modelos de Walton (1973), Hackman e Oldham (1975), Westley (1979) e Werther e Davis (1983). Foi escolhido um quarto das questões de cada domínio do QWLQ-78 para compor o QWLQ-bref. A validação dessa versão abreviada, construída por Cheremeta et al. (2011), foi publicada na Revista Brasileira de Qualidade de Vida.

O questionário abreviado do QWLQ-78, o QWLQ-bref foi construído segundo o mesmo método de abreviação do questionário WHOQOL-bref, em que foi selecionado um quarto das questões de cada domínio, resultando em quatro questões do domínio físico/saúde, três do domínio psicológico, quatro do domínio pessoal e nove do domínio profissional.

Esse instrumento de pesquisa se justifica, portanto, devido a Organização Mundial de Saúde (OMS) ter incentivado tanto a criação quanto a utilização de instrumentos com um menor número de questões para a QVT. Além disso, o QWLQbref apresenta uma maior correlação com o escore global da QVT do que o QWLQ78 (CHEREMETA et al., 2011), e isto justifica a escolha do QWLQ-bref na perspectiva dos eletricitários. 
A pesquisa foi aplicada presencialmente pelos pesquisadores. Durante a realização da pesquisa foram destacados os objetivos da pesquisa e suas finalidades. Os respondentes deveriam levar em consideração as duas últimas semanas de trabalho. Aos que concordavam em participar, eram distribuídos os questionários e recolhidos, posteriormente.

As respostas foram utilizadas em variações de escala likert de cinco pontos, em que os sentidos das perguntas abrangiam de uma pontuação muito ruim até uma pontuação muito boa. Conforme resultados dos índices, classificou-se cada um entre índices muito insatisfatório (0 a 22,5), insatisfatório (22,5 a 45), classificação neutra (45 a 55), satisfatório $(55$ a 77,5) e muito insatisfatório (77,5 a 100).

A organização pesquisada é responsável por fornecer os seguintes serviços:

a) manutenção de linhas de transmissão e subestações energizadas - linha viva (Iv);

b) lavagem de isoladores pelo método telecomandado de linhas e redes de alta e de média tensão e de subestações energizadas;

c) poda de árvores em redes elétricas em baixas, médias e altas tensões energizadas;

d) manutenção preditiva de subestações;

e) manutenção preventiva e corretiva de equipamentos de subestação.

f) limpeza de pátio, área de brita e terreno da subestação; e

g) operação e manutenção de subestação de usina eólica.

A empresa conta com aproximadamente cento e cinquenta funcionários atuantes no Estado do Ceará, diretamente com as atividades supracitadas. No total, foram obtidas 41 respostas de trabalhadores que exercem operações diretamente relacionadas com energia elétrica, ocupando as seguintes funções: auxiliar de poda, chefe de turma de poda, chefe de turma LV, eletricista, podador/eletricista, eletrotécnico, eletricista de manutenção de subestação, mecânico eletricista, eletricista/motorista, motorista operador guindauto e podador. Esse número de respondentes se justifica dado a dificuldade de acesso a esses eletricitários.

Analisou-se, primeiramente, o teste ANOVA de medidas repetidas, aplicandose o teste de esfericidade de Mauchily, em que a hipótese se relacionava com a assunção da esfericidade. As variáveis analisadas representaram valor significativo, indicando rejeição da hipótese. Portanto, foi utilizado o teste Huynh-Feldt, identificando que as etapas do processo de comparação diferem entre si. Para verificar quais médias diferem entre si, realizou-se o teste de Fisher.

Para o tratamento dos dados, as respostas dos questionários impressos foram digitadas e organizadas com o uso do Microsoft Excel. Posteriormente, foi utilizado o software estatístico Statistical Package for the Social Sciences (SPSS) (versão 21.0). 


\section{Análise dos resultados}

Primeiramente, verifica-se o perfil dos respondentes da pesquisa, segundo os dados sociais e demográficos, dentre os quais se destacam idade, estado civil, escolaridade, idade em que entrou no mercado de trabalho, quantidade de filhos, renda familiar e nível de responsabilidade financeira.

Quanto à idade, 6 pessoas estão na faixa de 18 a 25 anos, 14 pessoas na faixa de 26 a 35 anos, 16 pessoas de 36 a 45 anos, quatro pessoas na faixa de 46 a 55 anos e uma pessoa com mais de 55 anos, totalizando assim 41 respondentes na amostra pesquisada. Percebe-se que a maioria dos respondentes apresenta a idade de 36 a 45 anos, representando um percentual de 39,02\% do total da amostra.

Com relação à distribuição por situação residencial, observa-se que 37 pessoas moram em família ou com parceiro(a) $(90,2 \%)$, duas pessoas moram sozinhas em seus domicílios (4,9\%), uma pessoa divide moradia com amigos(as) (2,4\%) e uma pessoa em outra situação, distinta das expostas anteriormente $(2,4 \%)$.

No que tange ao estado civil, 16 pessoas são casadas (39\%), 13 pessoas solteiras $(31,7 \%), 1$ pessoa separada $(2,4 \%)$ e 11 pessoas com união estável $(26,85 \%)$. Em sua maioria, os respondentes são casados ou possuem união estável, somando um total de 27 pessoas, sendo 65,8\% da amostra pesquisada. Em relação à distribuição de renda familiar, percebe-se que o maior percentual está representado por aqueles que ganham entre 1 e 2 salários mínimos, o que corresponde a $75,6 \%$ da amostra.

Pode-se perceber, ainda, que a maior parte dessa renda total familiar dos respondentes é dividida com outros indivíduos, pois 48,8\% responderam que são responsáveis por si próprios, mas parcialmente responsáveis por outra pessoa. Porém, 39\% responderam que são totalmente responsáveis por si próprios e por outras pessoas. A idade de ingresso no mercado de trabalho identificou que na amostra pesquisada 23 respondentes começaram a trabalhar antes dos 18 anos, representando 56,1\%. Enquanto que 18 respondentes começaram a trabalhar depois dos 18 anos, 43,9\%. A maioria desses trabalhadores possui até o Ensino Médio completo, sendo que $34,2 \%$ até o Ensino Fundamental (TABELA 1).

Tabela 1 - Distribuição por escolaridade

\begin{tabular}{lcc}
\hline \multicolumn{1}{c}{ ITEM } & N & $\%$ \\
\hline Alfabetização Completa & 2 & $4,9 \%$ \\
Ensino Fundamental Incompleto & 9 & $22,0 \%$ \\
Ensino Fundamental Completo & 3 & $7,3 \%$ \\
Ensino Médio Incompleto & 8 & $19,5 \%$ \\
Ensino Médio Completo & 17 & $41,5 \%$ \\
Graduação Incompleta & 2 & $4,9 \%$ \\
Graduação Completa & 0 & $0,0 \%$ \\
Pós-Graduação Completa & 0 & $0,0 \%$ \\
Total & 41 & $100 \%$ \\
\hline
\end{tabular}

Fonte: Elaborada pelos autores. 
Observa-se que o perfil típico dos eletricitários pode ser descrito como homem, casado ou com união estável, porém parcialmente responsável financeiramente, com a renda familiar em até dois salários mínimos, possuindo nível de formação até o Ensino Médio completo.

Em relação ao primeiro objetivo específico desta pesquisa, realiza-se a análise dos indicadores do domínio físico/saúde de QVT. Conforme Reis Junior, Pilatti e Pedroso (2012), nesse domínio são analisados os aspectos relacionados à saúde, às doenças e aos hábitos saudáveis dos trabalhadores (TABELA 2).

Tabela 2 - Análise do domínio físico/saúde

\begin{tabular}{|c|c|c|c|c|c|}
\hline \multirow{3}{*}{ PERGUNTA } & \multicolumn{5}{|c|}{ Frequências } \\
\hline & Discordo & $\begin{array}{c}\text { Discordo } \\
\text { Parcialmente }\end{array}$ & Neutro & $\begin{array}{l}\text { Concordo } \\
\text { Parcialmente }\end{array}$ & Concordo \\
\hline & 1 & 2 & 3 & 4 & 5 \\
\hline \multirow{6}{*}{$\begin{array}{l}\text { Em que medida você } \\
\text { avalia seu sono? } \\
\text { Em que medida algum } \\
\text { problema de sono } \\
\text { prejudica seu trabalho? } \\
\text { Suas necessidades } \\
\text { fisiológicas básicas são } \\
\text { satisfeitas } \\
\text { adequadamente? }\end{array}$} & 0 & 0 & 8 & 23 & 9 \\
\hline & $0,00 \%$ & $0,00 \%$ & $19,50 \%$ & $56,10 \%$ & $22,00 \%$ \\
\hline & 20 & 10 & 7 & 3 & 1 \\
\hline & $48,80 \%$ & $24,40 \%$ & $17,10 \%$ & $7,30 \%$ & $2,40 \%$ \\
\hline & 0 & 4 & 14 & 12 & 10 \\
\hline & $0,00 \%$ & $9,80 \%$ & $34,10 \%$ & $29,30 \%$ & $24,40 \%$ \\
\hline Em que medida você & 0 & 1 & 18 & 15 & 7 \\
\hline $\begin{array}{l}\text { se sente confortável no } \\
\text { seu trabalho? }\end{array}$ & $0,00 \%$ & $2,40 \%$ & $43,90 \%$ & $36,60 \%$ & $17,10 \%$ \\
\hline
\end{tabular}

Fonte: Elaborada pelos autores.

De acordo com os dados, $56,10 \%$ da amostra avaliaram seu sono como bom, em que $48,8 \%$ afirmaram que o trabalho não prejudica o seu sono. Isso quer dizer que para um pouco mais da metade da amostra, o trabalho prejudica de alguma forma seu sono, variando a intensidade da forma como prejudica. Além disso, apenas 9,8\% responderam que suas necessidades fisiológicas não são totalmente satisfeitas, $34,10 \%$ apontaram que essas necessidades são medianamente ser satisfeitas e mais da metade afirmou que suas necessidades fisiológicas conseguem ser satisfatoriamente supridas.

Nota-se que um número significativo de eletricitários sente, conforme os resultados obtidos, certo desconforto no ambiente de trabalho, em que (43,9\%) se sentem medianamente confortáveis. Pode-se atrelar isso à presença da periculosidade nas atividades realizadas com energia elétrica. Apesar disso, o índice de conforto no trabalho não foi negativo, associando-se esse fator a um forte crescimento da segurança no trabalho no setor elétrico. Conforme o relatório da Fundação COGE (2013), percebe-se que os números de acidentes no trabalho vêm diminuindo cada vez mais nas empresas, devido a esse maior investimento. 
Maslow (1971) afirma que as necessidades básicas são essenciais para satisfação e qualidade de vida do indivíduo no trabalho. De acordo com os níveis obtidos no domínio físico/saúde, os eletricitários conseguem satisfazer essas necessidades.

Tabela 3 - Medidas descritivas do domínio físico/saúde

\begin{tabular}{cccccccc}
\hline Domínio & Média & $\begin{array}{c}\text { Desvio } \\
\text { padrão }\end{array}$ & $\begin{array}{c}\text { Coeficiente de } \\
\text { variação }\end{array}$ & $\begin{array}{c}\text { Valor } \\
\text { mínimo }\end{array}$ & $\begin{array}{c}\text { Valor } \\
\text { máximo }\end{array}$ & $\begin{array}{c}\text { Amplit } \\
\text { ude }\end{array}$ & $\begin{array}{c}\text { Índice de } \\
\text { QVT }\end{array}$ \\
\hline $\begin{array}{c}\text { Físico/ } \\
\text { Saúde }\end{array}$ & 3,872 & 0,613 & $15,82 \%$ & 2,500 & 5,000 & 2,500 & $71,8 \%$ \\
\hline
\end{tabular}

Fonte: Elaborada pelos autores.

No entanto, de acordo com o primeiro objetivo específico, neste artigo, observase que o índice de QVT geral desse domínio resultou em um nível satisfatório de aspectos físicos e de saúde na qualidade de vida no trabalho dos eletricitários, conforme abordado por Fernandes (1996), e isto possibilita rejeitar a H1: Os eletricitários possuem índices neutros de QVT para o domínio físico/saúde.

Além do mais, esse resultado contrapõe a pesquisa de Simmonds (2015), o qual investigou a QVT de 110 motoristas de transportes de cargas em trânsito, em que se retratou que as condições de trabalho e saúde foram consideradas insatisfatórias pelos investigados.

Em relação ao segundo objetivo específico, analisam-se os índices do domínio profissional para QVT. De acordo com Reis Junior, Pilatti e Pedroso (2012), o domínio psicológico integra os aspectos relacionados à satisfação pessoal, ao espírito de camaradagem, à motivação, ao orgulho e à liberdade de expressão.

A seguir, seguem os índices de QVT para o domínio psicológico na amostra (TABELA 4).

Tabela 4 - Frequências dos indicadores referentes ao domínio psicológico

\begin{tabular}{lccccc}
\hline \multicolumn{1}{c}{ PERGUNTA } & $\mathbf{1}$ & $\mathbf{2}$ & $\mathbf{3}$ & $\mathbf{4}$ & $\mathbf{5}$ \\
\hline Em que medida você avalia sua & 0 & 2 & 15 & 16 & 8 \\
motivação para trabalhar? & $0,00 \%$ & $4,90 \%$ & $36,60 \%$ & $39,00 \%$ & $19,50 \%$ \\
Como você avalia sua liberdade & 0 & 2 & 19 & 12 & 8 \\
de expressão no seu trabalho? & $0,00 \%$ & $4,90 \%$ & $46,30 \%$ & $29,30 \%$ & $19,50 \%$ \\
Em que medida você avalia o & 0 & 2 & 10 & 13 & 16 \\
orgulho pela sua profissão? & $0,00 \%$ & $4,90 \%$ & $24,40 \%$ & $31,70 \%$ & $39,00 \%$ \\
\hline
\end{tabular}

Fonte: Elaborada pelos autores.

Quanto à motivação no trabalho, a maioria dos eletricitários ficou entre uma motivação mediana $(36,6 \%)$ e satisfatória (39\%) para trabalhar. Hackman e Oldham (1975) defendem que há maior motivação no trabalho quando os trabalhadores conseguem perceber a responsabilidade e significância no seu trabalho, além do conhecimento dos reais resultados do mesmo. 
Ao verificar o índice de liberdade de expressão no trabalho, percebe-se que $46,3 \%$ dos respondentes a caracterizou como mediana. Walton (1973) afirma que o autocontrole é essencial para o indivíduo se sentir bem na empresa. Observa-se que a motivação está fortemente ligada com a liberdade de expressão, na medida em que os resultados de motivação e de liberdade de expressão estão em sua maior parte entre intervalos similares.

Verifica-se ainda que 39\% da amostra sentem muito orgulho da sua profissão. Esse fato pode ser relacionado ao que Werther e Davis (1981) remetem ao afirmarem que o trabalho deve atingir as expectativas profissionais de um indivíduo, nem ultrapassando, nem sendo menos do que o esperado, gerando orgulho no trabalho. Verifica-se que o Índice de QVT é satisfatório para os indicadores psicológicos, e isto possibilita confirmar a H2: Os eletricitários possuem índices satisfatórios para 0 domínio psicológico.

Tabela 5 - Medidas descritivas do domínio psicológico

\begin{tabular}{cccccccc}
\hline Domínio & Média & $\begin{array}{c}\text { Desvio } \\
\text { padrão }\end{array}$ & $\begin{array}{c}\text { Coeficiente } \\
\text { de variação }\end{array}$ & $\begin{array}{c}\text { Valor } \\
\text { mínimo }\end{array}$ & $\begin{array}{c}\text { Valor } \\
\text { máximo }\end{array}$ & Amplitude & $\begin{array}{c}\text { Índice } \\
\text { de QVT }\end{array}$ \\
\hline Psicológico & 3,805 & 0,675 & $17,00 \%$ & 2,333 & 5,000 & 2,667 & $70,10 \%$ \\
\hline
\end{tabular}

Fonte: Elaborada pelos autores.

Dessa forma, esse índice satisfatório no domínio psicológico reforça, portanto, a liberdade de expressão dos indivíduos dentro da organização, o que, consequentemente, possibilita mais QVT para os eletricitários (WALTON, 1973; WESTLEY, 1979). Além disso, Conte (2003) enfatiza que métodos que elevem a autoestima dos funcionários, melhora a QVT dentro e fora do ambiente de trabalho.

No tocante ao terceiro objetivo específico da pesquisa, realiza-se a análise do domínio pessoal de qualidade de vida no trabalho. O domínio pessoal, corroborando a Reis Junior, Pilatti e Pedroso (2012), aborda fatores que estão relacionados à realização pessoal, relações sociais, meio ambiente e espiritualidade/ religião/ crenças pessoais de um indivíduo.

Tabela 6 - Frequências dos indicadores referentes ao domínio pessoal

\begin{tabular}{lccccc}
\hline \multicolumn{1}{c}{ PERGUNTAS } & $\mathbf{1}$ & $\mathbf{2}$ & $\mathbf{3}$ & $\mathbf{4}$ & $\mathbf{5}$ \\
\hline $\begin{array}{l}\text { Você se sente realizado com } \\
\text { o trabalho que faz? }\end{array}$ & 0 & 1 & 14 & 15 & 11 \\
$\begin{array}{l}\text { Como você avalia a qualidade } \\
\text { de sua relação com seus }\end{array}$ & $0,00 \%$ & $2,40 \%$ & $34,10 \%$ & $36,60 \%$ & $26,80 \%$ \\
$\begin{array}{l}\text { superiores e/ou } \\
\text { subordinados? }\end{array}$ & $0,00 \%$ & $4,90 \%$ & $29,30 \%$ & $48,80 \%$ & $17,10 \%$ \\
$\begin{array}{l}\text { Em que medida sua família } \\
\text { avalia seu trabalho? }\end{array}$ & 1 & 1 & 4 & 20 & 15 \\
$\begin{array}{l}\text { Em que medida você é } \\
\text { respeitado pelos seus colegas }\end{array}$ & $2,40 \%$ & $2,40 \%$ & $9,80 \%$ & $48,80 \%$ & $36,60 \%$ \\
e superiores? & 0 & 0 & 4 & 20 & 17 \\
\hline
\end{tabular}

Fonte: Elaborada pelos autores. 
Quanto à realização pessoal, o resultado apresentou maiores percentuais entre mediano $(34,10 \%$ da amostra) e bom $(36,60 \%$ da amostra). Sobre a qualidade nas relações com superiores e subordinados, os resultados demonstram que $48,8 \% 0$ consideraram bom, sendo equivalente ao percentual obtido referente ao respeito nas relações entre colegas e superiores. Walton (1973) defende o indicador de Integração social na organização do trabalho.

Westley (1979) afirma que a partir do momento que o trabalhador tem suas crenças pessoais ou religiosas ignoradas, ele tende a ficar mais desmotivado. Como a maioria responde que o nível de qualidade e respeito nas relações é bom, percebese que isso influiu no nível geral do domínio, tornando-o satisfatório. Dentre os eletricitários, $85,4 \%$ percebem que a família os apoia e avalia seu trabalho como bom.

Tabela 7 - Medidas descritivas do domínio pessoal

\begin{tabular}{llllllll}
\hline Domínio & Média & $\begin{array}{l}\text { Desvio } \\
\text { padrão }\end{array}$ & $\begin{array}{l}\text { Coeficiente } \\
\text { de } \\
\text { Variação }\end{array}$ & $\begin{array}{l}\text { Valor } \\
\text { mínimo }\end{array}$ & $\begin{array}{l}\text { Valor } \\
\text { máximo }\end{array}$ & Amplitude & $\begin{array}{l}\text { Índice } \\
\text { de QVT }\end{array}$ \\
\hline Pessoal & 4,006 & 0,534 & $13,32 \%$ & 2,750 & 5,000 & 2,250 & $75,15 \%$ \\
\hline
\end{tabular}

Fonte: Elaborada pelos autores.

No geral, os índices de QVT referentes aos indicadores pessoais foram satisfatórios, sendo o domínio que apresentou maior média dentre os quatro analisados na amostra pesquisada, consequentemente, aceitando-se a H3: Os eletricitários possuem índices satisfatórios para o domínio pessoal, o que coincide com a perspectiva de Westley (1979) e Limongi-França e Zaima (2002), que ressaltam que índices satisfatórios no domínio pessoal reduzem o absenteísmo e o desinteresse dos indivíduos.

Levando-se em conta o quarto objetivo específico, realiza-se a análise do domínio profissional de QVT. Reis Junior, Pilatti e Pedroso (2012) ressaltam que no domínio profissional são integralizados os aspectos organizacionais, que afetam na qualidade de vida dos trabalhadores, como os benefícios, as condições de trabalho, a imagem da empresa (orgulho), o plano de carreira, a aprendizagem, a cooperação entre níveis hierárquicos, a remuneração e a responsabilidade social. Os índices obtidos para esse domínio estão apresentados na Tabela 8.

Tabela 8 - Frequências dos indicadores referentes ao domínio profissional (Continua)

\begin{tabular}{|c|c|c|c|c|c|}
\hline \multirow[t]{2}{*}{ PERGUNTA } & \multicolumn{5}{|c|}{ Frequências } \\
\hline & 1 & 2 & 3 & 4 & 5 \\
\hline Como você avalia a sua & 0 & 5 & 14 & 15 & 7 \\
\hline $\begin{array}{l}\text { liberdade para criar coisas } \\
\text { novas? }\end{array}$ & $0,00 \%$ & $12,20 \%$ & $34,10 \%$ & $36,60 \%$ & $17,10 \%$ \\
\hline Como você avalia a & 0 & 6 & 10 & 19 & 6 \\
\hline $\begin{array}{l}\text { igualdade de tratamento } \\
\text { entre os funcionários? }\end{array}$ & $0,00 \%$ & $14,60 \%$ & $24,40 \%$ & $46,30 \%$ & $14,60 \%$ \\
\hline Em que medida você possui & 1 & 8 & 13 & 9 & 10 \\
\hline $\begin{array}{l}\text { orgulho da organização na } \\
\text { qual trabalha? }\end{array}$ & $2,40 \%$ & $19,50 \%$ & $31,70 \%$ & $22,00 \%$ & $24,40 \%$ \\
\hline
\end{tabular}


Continuação

\begin{tabular}{|c|c|c|c|c|c|}
\hline \multirow[t]{2}{*}{ PERGUNTA } & \multicolumn{5}{|c|}{ Frequências } \\
\hline & 1 & 2 & 3 & 4 & 5 \\
\hline Em que medida você está & 0 & 5 & 18 & 15 & 3 \\
\hline $\begin{array}{l}\text { satisfeito com seu nível de } \\
\text { participação nas decisões da } \\
\text { empresa? }\end{array}$ & $0,00 \%$ & $12,20 \%$ & $43,90 \%$ & $36,60 \%$ & $7,30 \%$ \\
\hline Você está satisfeito com o & 0 & 0 & 16 & 19 & 6 \\
\hline $\begin{array}{l}\text { seu nível de } \\
\text { responsabilidades no } \\
\text { trabalho? }\end{array}$ & $0,00 \%$ & $0,00 \%$ & $39,00 \%$ & $46,30 \%$ & $14,60 \%$ \\
\hline Você se sente satisfeito com & 2 & 3 & 12 & 14 & 10 \\
\hline $\begin{array}{l}\text { os treinamentos dados pela } \\
\text { empresa? }\end{array}$ & $4,90 \%$ & $7,30 \%$ & $29,30 \%$ & $34,10 \%$ & $24,40 \%$ \\
\hline Você se sente satisfeito com & 1 & 4 & 12 & 14 & 10 \\
\hline $\begin{array}{l}\text { a variedade de trabalhos que } \\
\text { realiza? }\end{array}$ & $2,40 \%$ & $9,80 \%$ & $29,30 \%$ & $34,10 \%$ & $24,40 \%$ \\
\hline Como você avalia o espírito & 0 & 0 & 5 & 21 & 14 \\
\hline $\begin{array}{l}\text { de camaradagem no seu } \\
\text { trabalho? }\end{array}$ & $0,00 \%$ & $0,00 \%$ & $12,20 \%$ & $51,20 \%$ & $34,10 \%$ \\
\hline $\begin{array}{l}\text { O quanto você está satisfeito } \\
\text { com sua qualidade de vida } \\
\text { no trabalho? }\end{array}$ & $\begin{array}{c}0 \\
0,00 \%\end{array}$ & $\begin{array}{c}2 \\
4,90 \%\end{array}$ & $\begin{array}{c}13 \\
31,70 \%\end{array}$ & $\begin{array}{c}19 \\
46,30 \%\end{array}$ & $\begin{array}{c}7 \\
17,10 \%\end{array}$ \\
\hline
\end{tabular}

Fonte: Elaborada pelos autores.

Quanto à liberdade de criar coisas novas, a maior parte respondeu de mediano $(34,1 \%)$ a bom $(36,6 \%)$. Além disso, o nível de responsabilidade no trabalho e a satisfação com a variedade de tarefas tiveram resultados bons, representando $46,3 \%$ e $34,1 \%$ da amostra, respectivamente. Quanto ao nível de participações nas decisões da empresa, a maior parte avaliou como mediano (43,90\%). Esses indicadores remetem à teoria de Westley (1979), que afirma que a organização deve proporcionar ao indivíduo a oportunidade e autonomia para variar suas tarefas, objetivando que o mesmo não fique alienado e desinteressado com o passar do tempo.

Conforme Werther e Davis (1983), a QVT organizacional, ou seja, os indicadores profissionais se referem ao esforço que a empresa faz com o objetivo de melhorar a QVT dos trabalhadores, deixando os cargos menos monótonos e mais satisfatórios. $O$ indicador sobre a quantidade de treinamentos está ligado a essa teoria, em que $34,1 \%$ dos eletricitários responderam que a quantidade de treinamentos oferecida pela organização é boa. No setor elétrico, faz-se necessária a continuidade de treinamentos para funcionários, devido ao cuidado com a segurança no trabalho e ao desenvolvimento das tecnologias nessa área.

O orgulho pela empresa teve uma classificação em sua maior parte mediana $(31,7 \%)$. Walton (1973) remete que o trabalho deve ser uma atividade social que traga orgulho para as pessoas em participar de uma organização. Quanto ao espírito de camaradagem e a igualdade de tratamento entre os funcionários, um pouco mais da metade da amostra analisou que é boa, atingindo os percentuais respectivamente de $51,2 \%$ e $46,3 \%$. 
A pergunta chave desse questionário, que interroga sobre como o respondente percebe o seu nível de Qualidade de Vida no trabalho, apresentou (46,3\%) da amostra avaliando-a como boa, seguido de $31,7 \%$ das respostas com classificação mediana. Walton (1973) e Westley (1979) defendem que a remuneração e o plano de carreira são essenciais para uma boa QVT, além disso, afirmam que a grande maioria das atitudes tomadas pelos trabalhadores depende do seu ganho financeiro e da sua prospecção de futuro na empresa. Portanto, quanto a esses indicadores, os eletricitários perceberam, em sua maioria, como bom, rejeitando-se, por sua vez, $\mathrm{H} 4$ : Os eletricitários possuem índices neutros para o domínio profissional.

Tabela 9 - Medidas descritivas do domínio profissional

\begin{tabular}{cccccccc}
\hline Domínio & Média & $\begin{array}{c}\text { Desvio } \\
\text { padrão }\end{array}$ & $\begin{array}{c}\text { Coeficiente } \\
\text { de variação }\end{array}$ & $\begin{array}{c}\text { Valor } \\
\text { mínimo }\end{array}$ & $\begin{array}{c}\text { Valor } \\
\text { máximo }\end{array}$ & Amplitude & $\begin{array}{c}\text { Índice } \\
\text { de } \\
\text { QVT }\end{array}$ \\
\hline Profissional & 3,683 & 0,577 & $15,66 \%$ & 2,778 & 5,000 & 2,222 & $67,07 \%$ \\
\hline
\end{tabular}

Fonte: Elaborada pelos autores.

Diante disso, retrata-se, por meio do domínio profissional, que os eletricitários sentem de alguma forma prazer em executar seus trabalhos, seja por identidade pessoal, social, ou por se sentirem integrados a algum processo específico, reduzindo, portanto, o absenteísmo e isto, consequentemente, impacta na QVT desses indivíduos, o que concorda com a perspectiva de Limongi-França e Zaima (2002) e Moraes (2006).

De modo geral, observa-se que os eletricitários apresentam um nível satisfatório de QVT, por meio da análise dos domínios físico/saúde, psicológico, pessoal e profissional, que resultaram em indicadores com bons resultados.

Ao considerar as médias dos domínios, observa-se que o domínio pessoal é o fator de qualidade de vida no trabalho que mais está presente nos eletricitários. Entretanto, para assumir estatisticamente tal representação, deve-se analisar o teste ANOVA de medidas repetidas.

Para identificar as diferenças entre as etapas do processo de comparação das médias, utilizou-se da ANOVA de medidas repetidas. Este uso decorre pelos domínios serem relacionado às informações do indivíduo. No processo de análise da ANOVA de médias repetidas, primeiro se analisa o teste de esfericidade de Mauchily o qual tem como hipótese a assunção de esfericidade. Neste contexto, as variáveis analisadas apresentaram valor significativo, indicando rejeição da hipótese; assim, para a análise da diferença de variâncias foi utilizado, em vez do usual teste $F$ (usado para quando a hipótese de esfericidade é assumida), o teste Huynh-Feldt. Identificouse que as etapas do processo de comparação diferem-se (TABELA 10). 
Tabela 10 - Teste de comparação das médias

\begin{tabular}{ccccc}
\hline \multicolumn{1}{c}{ Testes } & F & Sig. & ObservedPower $^{\mathbf{a}}$ \\
\hline & $\begin{array}{c}\text { Esfericidade } \\
\text { assumida }\end{array}$ & 25,391 &, 000 & 1,000 \\
Etapas do Processo de & $\begin{array}{c}\text { Greenhouse- } \\
\text { Comparação }\end{array}$ & 25,391 &, 000 & 1,000 \\
& Geisser & &, 000 & 1,000 \\
& Huynh-Feldt & 25,391 &, 000 & 0,998 \\
\hline
\end{tabular}

Fonte: Elaborada pelos autores.

No entanto, a partir dessa indicação, para identificar quais médias diferem entre si, realizou-se o teste de Fisher que é similar ao teste t em pares. A seguir, seguem os resultados de acordo com o teste de Fisher (TABELA 11).

Tabela 11 - Teste de Fisher para comparação dos domínios, dois a dois

\begin{tabular}{cccc}
\hline (I) Domínio 1 & $(\mathbf{J})$ Domínio 2 & Diferença (I-J) & Valor $\boldsymbol{p}$ \\
\hline \multirow{2}{*}{ Domínio físico } & Domínio psicológico & $-0,488^{*}$ & 0 \\
& Domínio pessoal & $-0,713^{*}$ & 0 \\
& Domínio profissional & $-0,364^{*}$ & 0 \\
Domínio & Domínio físico & $0,488^{*}$ & 0 \\
psicológico & Domínio pessoal & $-0,226^{*}$ & 0,016 \\
& Domínio profissional & 0,124 & 0,197 \\
Domínio pessoal & Domínio físico & $0,713^{*}$ & 0 \\
& Domínio psicológico & $0,226^{*}$ & 0,016 \\
Domínio & Domínio profissional & $0,350^{*}$ & 0 \\
profissional & Domínio físico & $0,364^{*}$ & 0 \\
& Domínio psicológico & $-0,124$ & 0,197 \\
& Domínio pessoal & $-0,350^{*}$ & 0 \\
\hline
\end{tabular}

Fonte: Elaborada pelos autores.

Esse teste é utilizado para se comparar todos pares de médias, dois a dois. É indicado quando o tamanho das duas amostras independentes é pequeno e consiste em determinar a probabilidade exata de ocorrência de uma frequência observada, ou de valores mais extremos.

Conforme os valores $\mathrm{p}$ 0,000 foram identificados que os domínios diferem entre si, exceto o domínio psicológico em relação ao domínio profissional. Pela Tabela 11 foi possível identificar que o domínio pessoal é o mais identificado pelos respondentes, assumindo estatisticamente essa representatividade. 


\section{Considerações finais}

A qualidade de vida no trabalho se apresentou, portanto, como um tema em crescimento devido à exigência dos trabalhadores em melhores condições de trabalho. Além disso, a QVT busca aprimorar os níveis de produtividade dos indivíduos gerando, consequentemente, uma reciprocidade entre os interesses da organização e dos trabalhadores.

Em consonância com o objetivo deste estudo, que foi analisar a QVT de eletricitários do Estado do Ceará, destacou-se como fator importante presente nas atividades desses trabalhadores a periculosidade. Por meio da análise desta e dos acidentes de trabalho que são ocasionados, percebeu-se quais são as consequências de lidar com esse tipo de atividade.

De acordo com os dados da pesquisa, os eletricitários possuem, por sua vez, um nível satisfatório de qualidade de vida no trabalho. Esse resultado foi obtido por meio das análises dos domínios, o que permitiu atingir os objetivos da pesquisa.

Quanto ao primeiro objetivo específico, analisar o domínio físico/saúde, observou-se que o mesmo resultou em um nível satisfatório de QVT, rejeitando-se, então, H1: Os eletricitários possuem índices neutros de QVT para o domínio físico/saúde. No tocante ao segundo objetivo específico, investigar os níveis de QVT sobre o domínio psicológico, o domínio psicológico resultou em índices satisfatórios para a amostra, o que possibilitou a aceitação da H2: Os eletricitários possuem índices satisfatórios para o domínio psicológico.

Para o terceiro objetivo específico, avaliar os requisitos de QVT sobre o domínio pessoal, o domínio pessoal obteve um resultado satisfatório, e isto permitiu aceitar H3: Os eletricitários possuem índices satisfatórios para o domínio pessoal. Quanto ao quarto objetivo específico, investigar os índices de QVT sobre o domínio profissional, o domínio profissional resultou em níveis satisfatórios de QVT, o que rejeitou H4: Os eletricitários possuem índices neutros para o domínio profissional.

O mercado exige cada vez mais pessoas competentes, que exerçam funções e tarefas complexas e qualificadas. As ações voltadas à QVT envolvem, por sua vez, bem-estar pessoal, motivação, satisfação, práticas de atividade física, prevenção de doenças e muitas outras ações. Diante disso, amplia-se a produtividade e, como consequência, reduz o absenteísmo e os gastos organizacionais.

Esses achados contribuem, diretamente, para o campo dos estudos relacionados à QVT, alinhando-se, sobretudo, os domínios físico/saúde, psicológico, pessoal e profissional da QVT na perspectiva dos eletricitários, os quais trabalham diretamente em atividades perigosas. Além disso, os resultados fornecem informações para que os gestores organizacionais possam identificar o que impacta na QVT dos eletricitários. As ações voltadas para QVT devem ser implantadas, mantidas e vivenciadas por todos os indivíduos da organização.

Este estudo pode ser considerado um instrumento de diagnóstico para gestores de empresas do setor elétrico, em que foi possível analisar quais os fatores necessitam de maior investimento, a fim de que os eletricitários se sintam mais motivados para trabalhar. Este estudo apresentou limitações diante da dificuldade de acesso aos eletricitários. Diante disso, são recomendados para futuros estudos que sejam investigados mais eletricitários, bem como para que haja uma maior análise dos indicadores, sobretudo por meio de análises qualitativas relacionadas à QVT. 


\section{Referências}

BABBIE, E. Métodos de pesquisa de survey. 3. Ed. Belo Horizonte: UFMG, 2005.

BRASIL. Lei № 12.740, de 08 de dezembro de 2012. Altera o art. 193 da Consolidação das Leis do Trabalho - CLT, aprovada pelo Decreto-Lei № 5452, de 1 de maio de 1943, a fim de redefinir os critérios para a caracterização das atividades ou operações perigosas, e revoga a Lei $n^{\circ} 7369$, de 20 de setembro de 1985. Diário Oficial [da] República Federativa do Brasil, Brasília, DF, 9dez. 2012. Disponível em: $<$ http://www.planalto.gov.br/ccivil_03/_ato2011-2014/2012/lei//12740.htm>. Acesso em: 3 nov. 2014.

BRASIL. Ministério do Trabalho e Emprego. NR 16 - Atividades e Operações Perigosas, 2014.Diário Oficial [da] República Federativa do Brasil, Brasília, DF, 14.out. $2014 \quad$ Disponível em: <http://portal.mte.gov.br/data/files/8A7C816A48EC2EA401490E9B6BB80A19/NR16\%20(atualizada\%202014)\%20Motocicleta.pdf> Acesso em: 3 nov. 2014.

BRASIL. Ministério do Trabalho e Emprego. NR 10 - Segurança em Instalações e Serviços em Eletricidade. Diário Oficial [da] República Federativa do Brasil, Brasília, DF, 8.set. $2014 . \quad$ Disponível em:<http://portal.mte.gov.br/data/files/8A7C812D308E216601310641F67629F4/nr_1 0.pdf >. Acesso em: 3 nov. 2014.

BRASIL. Portaria no 1.078 de 16 de julho de 2014. Aprova o Anexo 4 - Atividades e operações perigosas com energia elétrica - da Norma Regulamentadora $n .{ }^{\circ} 16$ Atividades e Operações Perigosas. Diário Oficial [da] República Federativa do Brasil, Brasília, DF, 17.jul. 2014 Disponível em: <http://portal.mte.gov.br/data/files/FF80808147596147014759D205D84B45/Portaria $\% 20$ n.\%C2\%BA\%201078\%20(Nova\%20NR-16\%20-\%20Anexo\%20IV).pdf>. Acesso em: 3 nov. 2014.

BORGES-ANDRADE, J. E.; ZANELLI, J. C. Desafios metodológicos da pesquisa em Psicologia Organizacional e do Trabalho. Estudos de Psicologia (Natal), v. 7, p. 3$5,2002$.

CHEREMETA, M. et al. Construção da versão abreviada do QWLQ-78: um instrumento de avaliação da qualidade de vida no trabalho - Revista Brasileira de Qualidade de Vida, v. 3, n. 1, 2011.

CODO, W. Educação: Trabalho e carinho. Burnout, a síndrome da desistência do educador, que pode levar à falência da educação. Petrópolis: Vozes, 1999.

CONTE, A. L. Qualidade de vida no trabalho. Revista FAE business, v. 7, p. 32-34, 2003.

DAVIS W. B.; WERTHER, K. Administração de pessoal e recursos humanos. São Paulo: McGraw-Hill, 1983. 
EFRATY, D; SIRGY, M. J.; CLAIBORNE, C. B. The effects of personal alienation on organizational identification: a quality-of-work-life model. Journal of Business and Psychology, v. 6, n. 1, p. 57-78, 1991.

FARQUHAR, M. Definitions of quality of life: a taxonomy. Journal of Advanced Nursing, Oxford, 1995.

FUNDAÇÃO COGE. Segurança e Saúde no Trabalho. Relatório de Estatísticas de Acidentes no Setor Elétrico Brasileiro. Rio de Janeiro, 2013.

GRAY, D. E. Pesquisa no mundo real. 2. Ed. Porto Alegre: Penso, 2012.

GRUPO WHOQOL. Versão em português dos instrumentos de avaliação da qualidade de vida (WHOQOL). Faculdade de Medicina da UFRGS, 1998.

HACKMAN, J. R.; OLDHAM, G. R. Development of the job diagnostic survey. In: Journal of Applied Psychology. v. 60, n. 2, p. 159-170, 1975.

HERZBERG, F. Mais uma vez: Como motivar seus funcionários? Harvard Business Review, 1987.

HUSE, E.; CUMMINGS, T. Organization development and change. St. Paul: West Publishing Company, 1985.

LIMONGI-FRANÇA, A. C.; ZAIMA, G.. Gestão de qualidade de vida no trabalhoGQVT: com ênfase em pessoas equipes e liderança. MANUAL de gestão de pessoas e equipes: estratégias e tendências. São Paulo: Gente, p. 215-238, 2002.

MANOJLOVICH, M.; LASCHINGER, H.. The nursing worklife model: Extending and refining a new theory. Journal of Nursing Management, v. 15, n. 3, p. 256-263, 2007.

MARTEL, J.; DUPUIS, G. Quality of work life: Theoretical and methodological problems, and presentation of a new model and measuring instrument. Social indicators research, v. 77, n. 2, p. 333-368, 2006.

MARQUEZE, E. C.; MORENO, C. R. C.. Satisfação no trabalho - uma breve revisão1. Política Editorial, v. 5409, n. 112, p. 69-79, 2005.

MASLOW, A. H. Motivation and personality. 2nd Ed. New York: Harper e Row, p. 369, 1971.

MAYO, E. The Social Problems of an Industrial Civilization. Boston: Harvard University, 1945.

MCGREGOR, D. M. The human side of enterprise. New York, McGraw-Hill, 1960.

MENDES,R. A.; LEITE,N. Ginástica laboral: princípios e aplicações práticas. São Paulo: Manole, 2004. 
MORAES, G. T. B. Qualidade de Vida no Trabalho: um estudo sobre prazer e sofrimento em uma multinacional na cidade de Ponta Grossa-PR. 2006. 83 p. 2014. Dissertação (Mestrado em Engenharia de Produção) - Universidade Federal do Paraná, Ponta Grossa-PR, 2006.

NADLER, D.; LAWLER, E. Quality of work life: perspectives and directions. In: Organization Dynamics. v. 1, n. 11, p. 20-30, 1983.

PEREIRA, E. F.; TEIXEIRA, C. S.; SANTOS, A. Qualidade de vida: abordagens, conceitos e avaliação. Revista brasileira de educação física e esporte, v. 26, n. 2, p. 241-250, 2012.

REIS JUNIOR, D. R.; PILATTI, L. A.; PEDROSO, B. Qualidade de vida no trabalho: construção e validação do questionário QWLQ-78. Revista Brasileira de Qualidade de Vida, v. 3, n. 2, 2012.

SILVA, C. V.; JÚNIOR, A. P. C. Qualidade De Vida No Trabalho. Revista Eletrônica Interdisciplinar, v. 1, n. 17, 2017.

SIMMONDS, E. G. S. Fatores determinantes da Qualidade de Vida no Trabalho de motoristas de transporte de cargas em trânsito pela região de Barra do Garças -MT. Anais... Congresso Internacional de Administração, Ponta Grossa, 2015.

WALTON, R. E. Quality of working life: what is it? In: Sloan Management Review. Massachusetts, v. 15, n. 1, p. 11-21, 1973.

WESTLEY, W. A. Problems and Solutions in the Quality of Working Life. In: Humans Relations, v. 32, n. 2, p. 111-123, 1979.

WHOQOL Group. World Health Organization. WHOQOL: measuring quality of life. Genebra: WHO, 1997. 